\title{
Cyclic voltammetric analysis of 2-styrylchromones: Relationship with the antioxidant activity
}

\author{
Ana Gomes ${ }^{a}$, Eduarda Fernandes ${ }^{a}$,* M. Beatriz Q. Garcia ${ }^{a}$, Artur M. S. Silva ${ }^{b}$, Diana C. G. A. Pinto ${ }^{\text {, }}$ \\ Clementina M. M. Santos ${ }^{\mathrm{b}}$, José A. S. Cavaleiro ${ }^{\mathrm{b}}$, José L. F. C. Lima ${ }^{\mathrm{a}}$ \\ a REQUIMTE, Departamento de Química-Física, Faculdade de Farmácia, Universidade do Porto, Rua Aníbal Cunha, 164, 4099-030 Porto, Portugal \\ ${ }^{\mathrm{b}}$ Departamento de Química, Universidade de Aveiro, 3810-193 Aveiro, Portugal
}

\begin{abstract}
A B S T R A C T
2-Styrylchromones (2-SC) are a chemical family of oxygen heterocyclic compounds, vinylogues of flavones (2-phenylchromones), whose occurrence in nature has been reported. Recently, several 2-SC derivatives were demonstrated to have antioxidant properties, namely, xanthine oxidase inhibition, hepatoprotection against pro-oxidant agents in cellular and non-cellular systems and scavenging activity against reactive oxygen and reactive nitrogen species (ROS and RNS). Considering these antioxidant properties, it may be hypothesised that the electrochemical redox behaviour of 2-SC contributes significantly to their activity. To test this hypothesis, the electrochemical behaviour of different 2-SC was studied, together with a number of flavonoids with well-known antioxidant activities, by cyclic voltammetry, and the results correlated to their ability to scavenge ROS and RNS.

The results obtained showed that 2-SC with a catecholic B-ring have a low oxidation peak potential corresponding to the oxidation of the $3^{\prime}, 4^{\prime}-\mathrm{OH}$ (catechol) moiety. The compounds with a phenolic B-ring have a common peak, with oxidation potential values of about $+0.4 /+0.5 \mathrm{~V}$ versus $\mathrm{Ag} / \mathrm{AgCl}$, corresponding to the oxidation of the $4^{\prime}-\mathrm{OH}$. The oxidation of the hydroxyl substituents in the A-ring generated peaks of higher potentials $(+0.7 /+0.8 \mathrm{~V}$ vs $\mathrm{Ag} / \mathrm{AgCl})$. The results from the scavenging assays were in agreement with those obtained from the cyclic voltammetry, that is, higher scavenging effects corresponded to lower values of oxidation potentials, with significant correlation coefficients. The values obtained for the studied flavonoids are in accordance with the literature, and reflect their relative antioxidant activity, when compared to the studied 2-SC. Thus, in this family of compounds, oxidation potentials obtained by cyclic voltammetry seem to be applicable as a general indicator of radical scavenging activity.
\end{abstract}

\section{Introduction}

2-Styrylchromones (2-SC) are a chemical family of oxygen heterocyclic compounds, vinylogues of flavones (2-phenylchromones), whose occurrence in nature has been reported. Only two natural 2-SC are known and they were extracted from the bluegreen algae Chrysophaeum taylori in the 1980s. ${ }^{1,2}$ Before and after the isolation of natural 2-SC, several analogues of these compounds have been synthesised and tested in different biological systems. The natural compounds were demonstrated to possess cytotoxic activity against leukaemia cells, ${ }^{1,2}$ and those obtained by synthesis exhibited antiallergic, ${ }^{3}$ antiviral, ${ }^{4}$ antitumour, ${ }^{5}$ and antagonism of A3 adenosine receptor ${ }^{6}$ properties. Recently, these compounds have also demonstrated antioxidant properties, namely, xanthine oxidase inhibition, ${ }^{7}$ hepatoprotection against pro-oxidant agents in cellular ${ }^{8}$ and non-cellular systems ${ }^{9}$ and scavenging activity

\footnotetext{
* Corresponding author. Tel.: +351 222078968; fax: +351 222004427

E-mail address: egracas@ff.up.pt (E. Fernandes).
}

against reactive oxygen and reactive nitrogen species (ROS and RNS). ${ }^{10}$

The capacity of phenolic compounds, especially the polyhydroxylated derivatives, to scavenge free radicals is intimately related to their effectiveness to donate hydrogen atoms (H). Electrochemical oxidation can conceivably be used as a model for the scavenging reaction, since both reactions involve the breaking of the same $\mathrm{O}-\mathrm{H}$ bond and the donation of $\mathrm{e}^{-}$and $\mathrm{H}^{+}{ }^{11}$ Indeed, oxidation potentials have been correlated with the antioxidant power of phenolic compounds, particularly the flavonoids. ${ }^{11-15}$

Cyclic voltammetry is a widely used electroanalytic technique that allows determining the redox properties of molecules in a solution. Experimentally, the potential of a working electrode is linearly scanned (vs a reference electrode, typically $\mathrm{Ag} / \mathrm{AgCl}$ ) from an initial value to a final value and back. Thus, forward and backwards electrochemical reactions can be studied. This technique has been used to study the electrochemical oxidation mechanisms of flavonolic compounds. ${ }^{16-18}$

The purpose of the present study was to use cyclic voltammetry to assess the electrochemical behaviour of different 2-SC (Table 1) 
Table 1

Chemical structures and oxidation potentials of the tested 2-styrylchromones and flavonoids

\begin{tabular}{|c|c|c|c|c|c|c|c|}
\hline \multirow[t]{2}{*}{ Compounds } & \multirow[t]{2}{*}{ Chemical structure } & \multirow[t]{2}{*}{$\mathrm{R}^{1}$} & \multirow[t]{2}{*}{$\mathrm{R}^{2}$} & \multirow[t]{2}{*}{$\mathrm{R}^{3}$} & \multirow[t]{2}{*}{$\mathrm{R}^{4}$} & \multicolumn{2}{|c|}{$E_{\mathrm{p}_{\mathrm{ox}}}(\mathrm{V})$ versus $\mathrm{Ag} / \mathrm{AgCl}$} \\
\hline & & & & & & 1st peak & 2nd peak \\
\hline \multicolumn{8}{|c|}{ 2-Styrylchromones } \\
\hline $1 \mathrm{~A}$ & & $\mathrm{OH}$ & $\mathrm{OH}$ & $\mathrm{OH}$ & $\mathrm{OH}$ & +0.169 & +0.762 \\
\hline 1B & & $\mathrm{OH}$ & $\mathrm{OH}$ & $\mathrm{H}$ & $\mathrm{OH}$ & +0.167 & +0.806 \\
\hline 1C & & $\mathrm{OH}$ & $\mathrm{OH}$ & $\mathrm{OH}$ & $\mathrm{H}$ & +0.183 & +0.819 \\
\hline 1D & & $\mathrm{OH}$ & $\mathrm{OH}$ & $\mathrm{H}$ & $\mathrm{H}$ & +0.173 & - \\
\hline $2 A$ & $\mathbf{R}^{4}$ & $\mathrm{OH}$ & $\mathrm{H}$ & $\mathrm{OH}$ & $\mathrm{OH}$ & +0.444 & +0.777 \\
\hline 2B & & $\mathrm{OH}$ & $\mathrm{H}$ & $\mathrm{H}$ & $\mathrm{OH}$ & +0.485 & - \\
\hline $2 C$ & 7 & $\mathrm{OH}$ & $\mathrm{H}$ & $\mathrm{OH}$ & $\mathrm{H}$ & +0.424 & - \\
\hline 2D & & $\mathrm{OH}$ & $\mathrm{H}$ & $\mathrm{H}$ & $\mathrm{H}$ & +0.495 & - \\
\hline 3A & 5 & $\mathrm{H}$ & $\mathrm{H}$ & $\mathrm{OH}$ & $\mathrm{OH}$ & +0.764 & - \\
\hline 3B & $\mathbf{R}^{3}$ & $\mathrm{H}$ & $\mathrm{H}$ & $\mathrm{H}$ & $\mathrm{OH}$ & +0.787 & - \\
\hline $3 C$ & & $\mathrm{H}$ & $\mathrm{H}$ & $\mathrm{OH}$ & $\mathrm{H}$ & +0.817 & - \\
\hline 3D & & $\mathrm{H}$ & $\mathrm{H}$ & $\mathrm{H}$ & $\mathrm{H}$ & - & - \\
\hline \multicolumn{8}{|l|}{ Flavonoids } \\
\hline Luteolin & & $\mathrm{OH}$ & $\mathrm{OH}$ & $\mathrm{OH}$ & $\mathrm{OH}$ & +0.223 & - \\
\hline Apigenin & $\mathbf{R}^{4}$ & $\mathrm{OH}$ & $\mathrm{H}$ & $\mathrm{OH}$ & $\mathrm{OH}$ & a & \\
\hline Chrysin & & $\mathrm{H}$ & $\mathrm{H}$ & $\mathrm{OH}$ & $\mathrm{OH}$ & +0.767 & - \\
\hline 5-OH Flavone & & $\mathrm{H}$ & $\mathrm{H}$ & $\mathrm{OH}$ & $\mathrm{H}$ & +0.807 & - \\
\hline 7-OH Flavone & & $\mathrm{H}$ & $\mathrm{H}$ & $\mathrm{H}$ & $\mathrm{OH}$ & +0.797 & - \\
\hline
\end{tabular}

${ }^{\text {a }}$ Not possible to determine $E_{\mathrm{p}_{\mathrm{ox}}}$.

in order to understand the mechanism behind the scavenging of ROS and RNS. Five flavones (luteolin, apigenin, chrysin, 5-hydroxyflavone and 7-hydroxyflavone) were also tested due to the similarities of their structures with those of 2-SC. This allowed to take advantage from the existing knowledge about flavonoids and helped to interpret the results.

\section{Results}

Cyclic voltammograms of 2-SC from group 1 (1A-1D) showed the permanent presence of a low potential oxidation peak (Table 1 ), with a correspondent reduction peak being detected in the reverse scan. Additionally, the compounds $\mathbf{1 A}, \mathbf{1 B}$ and $\mathbf{1 C}$ showed a second oxidation peak (see Fig. 1, for compound 1B, as a representative voltammogram).

The redox reaction that occurs at lower potential was studied in detail by analysing the change of the peak current $\left(I_{\mathrm{p}}\right)$ and the oxidation potential $\left(E_{\mathrm{p}}\right)$ with scan rate and $\mathrm{pH}$. The ratio between the reduction and the oxidation peak currents $\left(I_{\mathrm{p}_{\mathrm{red}}} / I_{\mathrm{p}_{\mathrm{ox}}}\right)$ tended to be smaller, less than unity, at low scan rate values, increasing at higher values, for compounds $\mathbf{1 A}$ and $\mathbf{1 B}$, and was practically invariable, and always less than unity, along the scan rate interval for com-

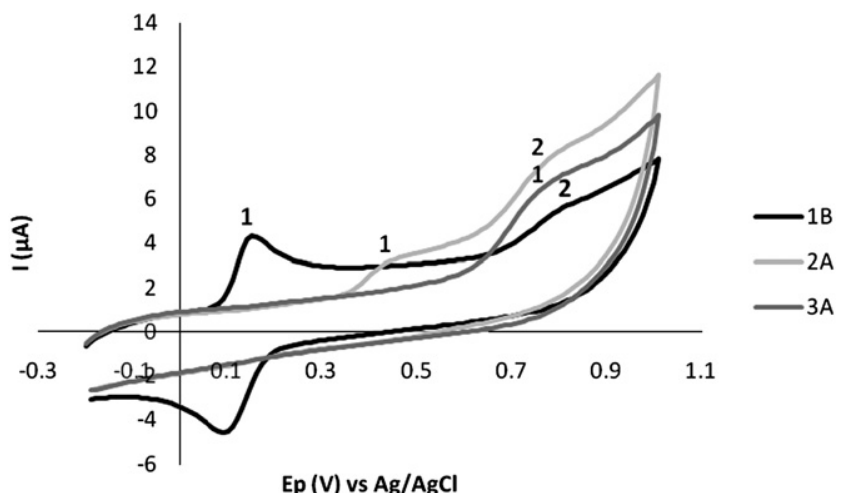

Figure 1. Cyclic voltammograms of compounds $\mathbf{1 B}, \mathbf{2 A}$ and $\mathbf{3 A}$ in $\mathrm{pH} 7.4$ phosphate buffer. Scan rate $100 \mathrm{mV} \mathrm{s}^{-1}$. pounds 1C and 1D. When the potential scan was inverted before the second oxidation peak was shown, that is, at $0.4 \mathrm{~V}$ versus $\mathrm{Ag} /$ $\mathrm{AgCl}$, that ratio became approximately 1 for all the compounds, indicating the reversibility of the electrochemical reaction (see Fig. 2, for compound $\mathbf{1 A}$, as a representative voltammogram). The oxidation and reduction peak potentials $\left(E_{\mathrm{p}_{\mathrm{ox}}}\right.$ and $\left.E_{\mathrm{p}_{\mathrm{red}}}\right)$ were practically invariable along the studied scan rate interval.

The $E_{\mathrm{p}_{\mathrm{ox}}}$ of the first peak was shown to be dependent on the $\mathrm{pH}$ in the range of 3.8-11, that is, an increase of the $\mathrm{pH}$ was associated with a decrease of the $E_{\mathrm{p}_{\mathrm{ox}}}$, as it was demonstrated for compound $1 \mathrm{~B}\left(E_{\mathrm{p}_{\mathrm{ox}}}=-0.046 \mathrm{pH}+0.539\right)$. For higher $\mathrm{pH}$ values $(>11)$ the electron transfer reaction was $\mathrm{pH}$ independent and the reduction peak tended to become smaller, being undetectable at the $\mathrm{pH}$ of 11.6 and beyond.

An oxidation peak with $E_{\mathrm{p}_{\mathrm{ox}}}$ values between +0.4 and $+0.5 \mathrm{~V}$ versus $\mathrm{Ag} / \mathrm{AgCl}$ was visible in the cyclic voltammograms of the compounds from group 2 (2A-2D). A second oxidation peak was observed at higher potentials for the compound $\mathbf{2 A}$ (Fig. 1). The compounds $\mathbf{3 A}-\mathbf{3 C}$ gave rise to an oxidation peak with $E_{\mathrm{p}_{\mathrm{ox}}}$ values comparable to those of the second peak of compounds 1A-1C and $\mathbf{2 A}$ (Fig. 1). These oxidation peaks appear to correspond to irrevers-

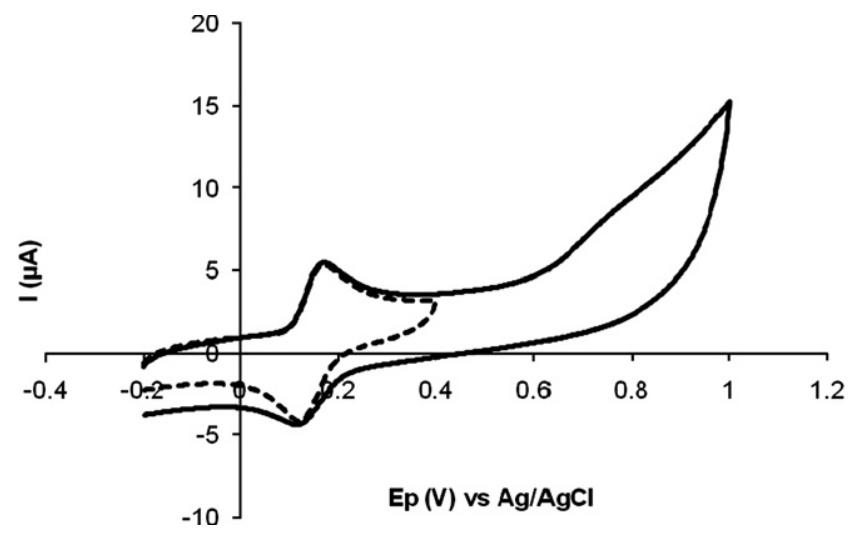

Figure 2. Cyclic voltammograms of compound $\mathbf{1 A}$ in pH 7.4 phosphate buffer: $(-)$ scan inversion at $1.0 \mathrm{~V}$ versus $\mathrm{Ag} / \mathrm{AgCl}$; (---) scan inversion at $0.4 \mathrm{~V}$ versus $\mathrm{Ag} / \mathrm{AgCl}$. Scan rate $100 \mathrm{mV} \mathrm{s}^{-1}$. 
ible processes, since no current was observed in the reverse scan. For compound 3D there were no detectable peaks (Table 1).

The cyclic voltammogram of luteolin presented one oxidation peak and a correspondent reduction peak. The flavones chrysin, 5-OH flavone and 7-OH flavones revealed a common oxidation peak, which appeared at potentials around $+0.8 \mathrm{~V}$ versus $\mathrm{Ag} / \mathrm{AgCl}$. Apigenin showed two possible oxidation peaks, although barely defined, not allowing the determination of the $E_{\mathrm{p}_{\mathrm{ox}}}$ values (Table 1 ).

\section{Discussion}

In the present study, the electrochemical behaviour of several 2-SC was evaluated for the first time. According to the literature related to studies with flavonoids, the first oxidation peak observed in the 2-SC 1A-1D corresponds to the oxidation of the $3^{\prime}, 4^{\prime}-\mathrm{OH}$ (catechol) moiety in the B-ring. ${ }^{16-18}$ The absence of a similar peak in the compounds lacking this catechol substituent supports this thesis. A detailed analysis of this peak indicated a reversible redox process with a coupled chemical reaction, also in accordance to previous reports for flavonoids. ${ }^{16,19}$ The observed dependence of the $E_{\mathrm{p}_{\mathrm{ox}}}$ of the first oxidation peak on the $\mathrm{pH}$ (demonstrated for

a<smiles>[R]C1=CC(=O)C(=O)C=C1</smiles><smiles>[R]c1cc([R])c2c(=O)cc(/C=C/c3ccc(O)c(O)c3)oc2c1</smiles>

Figure 3. (a) Mechanism of oxidation of catechol-like compounds. (b) Proposed oxidation mechanism of 2-styrylchromones. compound 1B) shows that, during reaction, not only electrons but also protons are released from the molecule. ${ }^{17,18}$ An increase in $\mathrm{pH}$ was associated with a decrease in the $E_{\mathrm{p}_{\mathrm{ox}}}$, meaning that at higher $\mathrm{pH}$ the compound is easily oxidised, thus, becoming a more efficient antioxidant. At $\mathrm{pH}>11$, this dependence no longer existed, indicating deprotonation of the molecule. ${ }^{17,18}$ When Lemanska et al. ${ }^{20}$ compared the calculated $\mathrm{O}-\mathrm{H}$ bond dissociation energies (BDE) and ionisation potentials (IP) in the nondeprotonated and the protonated forms of various hydroxyflavones, they verified that, especially the parameter reflecting the ease of electron donation, that is, the IP, and not the BDE for hydrogen atom donation, is greatly influenced by deprotonation. Thus, electron donation becomes the dominant mechanism of antioxidant action of hydroxyflavones after deprotonation.

It is known that the antioxidant capacity is conceivably related to the electrochemical behaviour, a low oxidation potential being indicative of a high antioxidant power. ${ }^{21}$ Accordingly, Firuzi et al. ${ }^{15}$ found a good negative correlation between the 'ferric reducing antioxidant power' (FRAP) and the oxidation potential of several flavonoids. Moreover, flavonoids with low half peak oxidation potentials showed higher antioxidant activity (measured by the inhibition of microsomal lipid peroxidation) than those with high potentials. ${ }^{11}$ Furthermore, it has been postulated that flavonoids, due to their lower redox potentials, are thermodynamically able to reduce highly oxidizing free radicals, such as superoxide, peroxyl, alkoxyl and hydroxyl radicals. ${ }^{14,22,23}$

The studied 2-SC had previously been tested for their antioxidant capacity by the determination of their scavenging activity against ROS and RNS, where some of them showed strong effects. ${ }^{10}$ By comparing the results from that study and the present one, the compounds with the lowest oxidation potentials (1A-1D) were also the most effective scavengers of ROS and RNS. These compounds have in common a cathecol group in the B-ring, which is known to be an important structural feature to the antioxidant activity. ${ }^{14,24}$ Of note, in the present study, luteolin showed an $E_{\mathrm{p}_{\mathrm{ox}}}$ slightly more positive than the catecholic 2-SC, corresponding, in theory, to a less efficient antioxidant activity than 2-SC. Indeed, in our previous work, ${ }^{10}$ luteolin was always a worse scavenger than 1A. Taking into account that these two compounds only differ in the styryl moiety, it is expected that this structural feature contributes positively to the reducing capacity of the molecule. The mechanism behind the reaction of catechol-like compounds with radical derivatives consists in a two electron two proton process with the production of an ortho-quinone (Fig. 3a). ${ }^{15,16,18}$ However, our cyclic voltammetry results suggest an oxidation reaction involving only one electron process. This phenomenon can be explained by the formation of a semiquinone (SQ) (or to use the more generic term, an aryloxyl radical), which undergoes

Table 2

ROS and RNS scavenging activity by $2-\mathrm{SC}^{10}$

\begin{tabular}{|c|c|c|c|c|c|c|}
\hline & $\mathrm{O}_{2}^{-\mathrm{a}}$ & $\mathrm{H}_{2} \mathrm{O}_{2}{ }^{\mathrm{b}}$ & $\mathrm{HOCl}^{c}$ & ${ }^{1} \mathrm{O}_{2}{ }^{\mathrm{d}}$ & $\mathrm{ONOO}^{-}$without $\mathrm{NaHCO}_{3}{ }^{\mathrm{c}}$ & $\mathrm{ONOO}^{-}$with $\mathrm{NaHCO}_{3}{ }^{\mathrm{c}}$ \\
\hline $1 \mathrm{~A}$ & $28.8 \pm 0.9$ & $66.7 \pm 2.2$ & $3.9 \pm 0.2$ & $2.3 \pm 0.4$ & $0.26 \pm 0.02$ & $0.63 \pm 0.03$ \\
\hline 1B & $18.9 \pm 1.2$ & $50.8 \pm 2.6$ & $18.0 \pm 1.8$ & $3.7 \pm 0.4$ & $0.30 \pm 0.03$ & $0.61 \pm 0.08$ \\
\hline 1C & $46.6 \pm 5.5$ & $67.9 \pm 1.2$ & $16.9 \pm 1.1$ & $1.9 \pm 0.3$ & $0.26 \pm 0.04$ & $0.51 \pm 0.05$ \\
\hline 1D & $42.4 \pm 6.4$ & $44.1 \pm 2.8$ & $31.2 \pm 1.5$ & $2.7 \pm 0.4$ & $0.24 \pm 0.02$ & $0.44 \pm 0.02$ \\
\hline $2 A$ & & $10.6 \pm 1.7$ & $8.5 \pm 0.3$ & $72.3 \pm 2.3$ & $1.25 \pm 0.14$ & $1.21 \pm 0.16$ \\
\hline 2B & $17.7 \pm 1.4$ & & $92.0 \pm 7.1$ & $93.4 \pm 18.3$ & $1.40 \pm 0.13$ & $1.65 \pm 0.16$ \\
\hline $2 \mathrm{C}$ & & $16.9 \pm 1.6$ & & $40.0 \pm 4.3$ & $1.04 \pm 0.04$ & $0.98 \pm 0.13$ \\
\hline 2D & $56.0 \pm 13.5$ & & & $105.0 \pm 5.1$ & $1.20 \pm 0.17$ & $1.23 \pm 0.19$ \\
\hline $3 \mathbf{A}$ & $125.0 \pm 2.9$ & & $5.7 \pm 0.7$ & $81.3 \pm 4.8$ & $46.6 \pm 7.0$ & $40.6 \pm 2.2$ \\
\hline 3B & $55.9 \pm 2.3$ & & $72.3 \pm 5.0$ & & & \\
\hline
\end{tabular}

a $\mathrm{IC}_{27}(\mu \mathrm{M})$.

b \% Effect at $125 \mu \mathrm{M}$

c $\mathrm{IC}_{50}(\mu \mathrm{M})$.

d $\mathrm{IC}_{30}(\mu \mathrm{M})$. 
disproportionation leading to the ortho-quinone formation and to the regeneration of the starting 2-SC (Fig. 3b). ${ }^{25,26}$

The 2-SC 2A-2D showed a common peak, with $E_{\mathrm{p}_{\mathrm{ox}}}$ values of about $+0.4 /+0.5 \mathrm{~V}$ versus $\mathrm{Ag} / \mathrm{AgCl}$, corresponding to the oxidation of the $4^{\prime}-\mathrm{OH}$ group in the B-ring. Although apigenin has a similar substituent, the presence of that peak was not clear in this flavone. Nevertheless, the comparison of the results obtained for 2D $\left(E_{\mathrm{p}_{\mathrm{ox}}}=+0.495 \mathrm{~V}\right.$ vs $\mathrm{Ag} / \mathrm{AgCl}$ ) and 3D (no detectable peaks), which only differ in the 4 '-OH group, prove that the observed oxidation peak results from the oxidation of this substituent. The difference in the behaviour of these phenolic 2-SC and apigenin is likely to lie on the styryl moiety, which facilitates the electron delocalization from the B-ring contributing for the stabilization of the phenoxy radical that is formed during the redox reactions. ${ }^{23,27}$ Accordingly, our group had already shown that apigenin was a worse scavenger of ROS and RNS than the 2-SC $\mathbf{2 A}$ and $\mathbf{2 B}$. $^{10}$

An oxidation peak with $E_{\mathrm{p}_{\text {ox }}}$ values around $+0.8 \mathrm{~V}$ versus $\mathrm{Ag}$ / $\mathrm{AgCl}$ was detected in the 2-SC 1A-1C, 2A and $\mathbf{3 A - 3 C}$ as well as in the flavonoids chrysin, 5-hydroxyflavone and 7-hydroxyflavone (Table 1). This peak results from the oxidation of the $5-\mathrm{OH}$ and/or 7-OH groups of the A-ring. The high $E_{\mathrm{p}_{\mathrm{ox}}}$ values point to a weak antioxidant capacity of the compounds that have hydroxyl substituents only in the A-ring. Indeed, the compounds 3A-3C, chrysin, 5hydroxyflavone and 7-hydroxyflavone have previously shown to be poor or even ineffective scavengers of ROS and RNS.

As expected, the compound 3D, with no hydroxyl substituents, showed no redox peaks.

Correlations between the $E_{\mathrm{p}_{\mathrm{ox}}}$ of the first peak (Table 1) and the scavenging activity against ROS and RNS (Table 2) were analysed by using the Pearson correlation test. Significant correlations were found for $\mathrm{H}_{2} \mathrm{O}_{2}$, singlet oxygen $\left({ }^{1} \mathrm{O}_{2}\right)$ and peroxynitrite (Table 3 ), indicating that the scavenging mechanism against these reactive species is based on redox reactions. No significant correlation was found for superoxide radical $\left(\mathrm{O}_{2}^{--}\right)$and hypochlorous acid $(\mathrm{HOCl})$.

In conclusion, the scavenging effects of the studied 2-SC are related to their electrochemical behaviour. Oxidation potentials can be used as a general indicator of radical scavenging ability. The catecholic and phenolic 2-SC are more easily oxidisable than the corresponding flavones, probably due to the improvement of the electron-donating capacity of the molecule caused by the styryl moiety.

\section{Experimental}

\subsection{Materials}

All the chemicals and reagents were of analytical grade. Luteolin, apigenin, 5-hydroxyflavone, 7-hydroxyflavone and aluminium oxide were obtained from Sigma-Aldrich. Chrysin was obtained from Aldrich. DMSO was obtained from Fluka. The other reagents were obtained from Merck.

\subsection{Cyclic voltammetry}

2-SC (1A-1D, 2A-2D and 3A-3D) were synthesised according to procedures described in the literature. ${ }^{28}$

Water purified by the Millipore Milli-Q system (conductivity $<0.1 \mu \mathrm{S} \mathrm{cm}^{-1}$ ) was used in the preparation of solutions. Flavonoids and 2-SC were dissolved in DMSO and further diluted in a supporting electrolyte, consisting of a $\mathrm{NaH}_{2} \mathrm{PO}_{4} / \mathrm{Na}_{2} \mathrm{HPO}_{4}$ buffer, $\mathrm{pH} 7.4$ (ionic strength of 0.2 ), reaching a final concentration of $0.1 \mathrm{mM}$. To determine the effect of $\mathrm{pH}$ on the first oxidation peak potential, for compound $\mathbf{1 B}$, the $\mathrm{pH}$ was varied from 3.8 to 12.5 . To cover the whole $\mathrm{pH}$ range, the following solutions were used
Table 3

Correlations between the $E_{\mathrm{p}_{\mathrm{ox}}}$ and the scavenging activity against ROS and RNS of the tested $2-\mathrm{SC}^{10}$
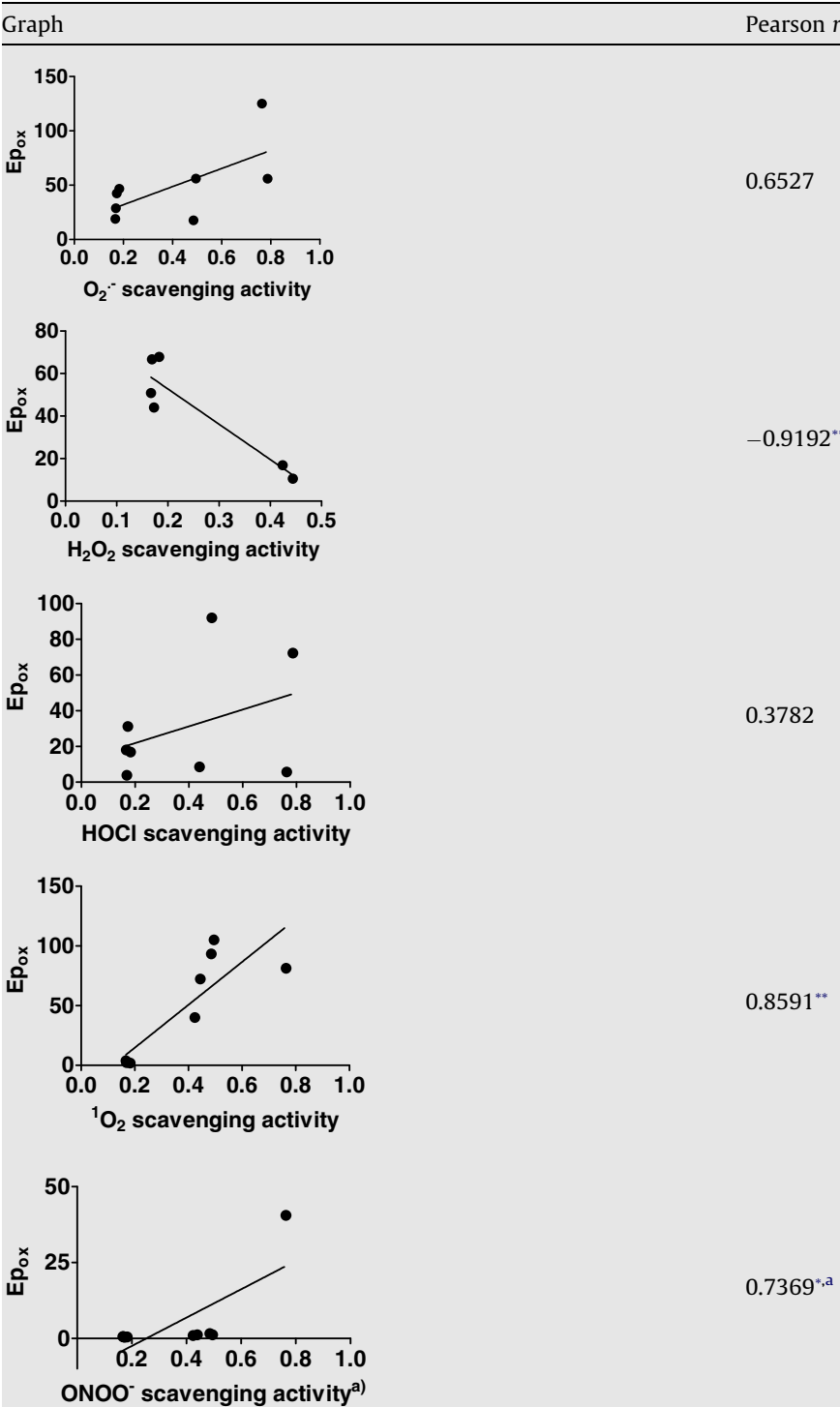

$0.7369^{*, a}$

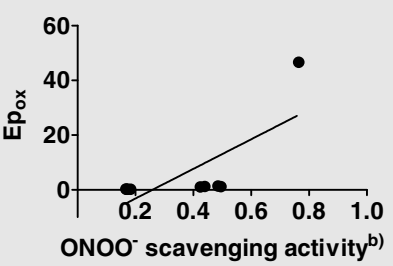

$0.7345^{*}$

a With bicarbonate.

b Without bicarbonate.

Significant at $p<0.05$

* Significant at $p<0.01$

as supporting electrolytes: $\mathrm{HCH}_{3} \mathrm{COO} / \mathrm{NaCH}_{3} \mathrm{COO}, \mathrm{NaH}_{2} \mathrm{PO}_{4} / \mathrm{Na}_{2} \mathrm{H}-$ $\mathrm{PO}_{4}, \mathrm{NH}_{4} \mathrm{Cl} / \mathrm{NH}_{3}, \mathrm{KCl} / \mathrm{NaOH}$.

Electrochemical measurements were carried out in an Autolab electrochemical system (Eco Chemie model PGSTAT 10), and data acquisition was accomplished through GPES software (Version 4.6). Voltammetric signals were recorded at room temperature. The working electrode was a glassy carbon electrode $(3.0 \mathrm{~mm}$ diameter), a $\mathrm{Ag} / \mathrm{AgCl}(\mathrm{KCl} 3 \mathrm{M})$ electrode was used as reference and a carbon electrode was used as auxiliar. The glassy carbon 
working electrode was polished with alumina $0.075 \mu \mathrm{m}$ aqueous slurry before every experiment. Cyclic voltammograms were obtained by a single cycle performed at a scan rate of $100 \mathrm{mV} \mathrm{s}^{-1}$. For the scan rate studies, the scan rate was varied from 10 to $200 \mathrm{mV} \mathrm{s}^{-1}$. Voltammetric scans were carried out in the potential interval of -0.2 to $+1.0 \mathrm{~V}$ versus $\mathrm{Ag} / \mathrm{AgCl}$.

\subsection{Statistical analysis}

Pearson's correlation test was performed using GraphPad Prism version 5.00 for Windows, GraphPad Software, San Diego, CA, USA, www.graphpad.com.

\section{Acknowledgements}

The authors acknowledge FCT and FEDER financial support for the Project POCI/QUI/59284/2004. Ana Gomes acknowledges FCT and FSE her Ph.D. Grant (SFRH/BD/23299/2005).

\section{References and notes}

1. Gerwick, W. H.; Lopez, A.; Van Dyune, G. D.; Clardy, J.; Ortiz, W.; Baez, A. Tetrahedron Lett. 1986, 27, 1979.

2. Gerwick, W. H. J. Nat. Prod. 1989, 52, 252.

3. Doria, G.; Romeo, C.; Forgione, A.; Sberze, P.; Tibolla, N.; Corno, M. L.; Cruzzola G.; Cadelli, G. Eur. J. Med. Chem. 1979, 14, 347.

4. Desideri, N.; Conti, C.; Mastromarino, P.; Mastropaolo, F. Antiviral Chem Chemother. 2000, 11, 373.

5. Brion, D.; Le Baut, G.; Zammatio, F.; Pierre, A.; Atassi, G.; Belachm, L. Chem Abstr. 1991, 116, 106092k

6. Karton, Y.; Jiang, J. L.; Ji, X. D.; Melman, N.; Olah, M. E.; Stiles, G. L.; Jacobson, K. A. J. Med. Chem. 1996, 39, 2293.
7. Fernandes, E.; Carvalho, F.; Silva, A. M. S.; Santos, C. M. M.; Pinto, D. C. G. A.; Cavaleiro, J. A. S.; Bastos, M. L. J. Enzyme Inhib. Med. Chem. 2002, 17, 45.

8. Fernandes, E.; Carvalho, M.; Carvalho, F.; Silva, A. M. S.; Santos, C. M. M.; Pinto, D. C. G. A.; Cavaleiro, J. A. S.; Bastos, M. L. Arch. Toxicol. 2003, 77, 500.

9. Filipe, P. Silva, A. M.; Morliere, P.; Brito, C. M.; Patterson, L. K. Hug G. L.; Silva, J. N.; Cavaleiro, J. A.; Maziere, J. C.; Freitas, J. P.; Santus, R. Biochem. Pharmacol. 2004, 67, 2207.

10. Gomes, A.; Fernandes, E.; Silva, A. M.; Santos, C. M.; Pinto, D. C.; Cavaleiro, J. A.; Lima, J. L. Bioorg. Med. Chem. 2007, 15, 6027.

11. van Acker, S. A.; van den Berg, D. J.; Tromp, M. N.; Griffioen, D. H.; van Bennekom, W. P.; van der Vijgh, W. J.; Bast, A. Free Radical Biol. Med. 1996, 20 , 331.

12. Rapta, P.; Misik, V.; Stasko, A.; Vrábel, I. Free Radical Biol. Med. 1995, 18, 901.

13. van Acker, S. A. B. E.; van Balen, G. P.; van den Berg, D. J.; Bast, A.; van der Vijgh, W. J. F. Biochem. Pharmacol. 1998, 56, 935.

14. Pietta, P. G. J. Nat. Prod. 2000, 63, 1035.

15. Firuzi, O.; Lacanna, A.; Petrucci, R.; Marrosu, G.; Saso, L. Biochim. Biophys. Acta 2005, 1721, 174.

16. Hendrickson, H. P.; Kaufman, A. D.; Lunte, C. E. J. Pharm. Biomed. Anal. 1994, 12, 325.

17. Janeiro, P.; Brett, A. M. O. Anal. Chim. Acta 2004, 518, 109.

18. Brett, A. M. O.; Ghica, M.-E. Electroanalysis 2003, 15, 1745

19. El-Shahawi, M. S.; Bashammakh, A. S.; El-Mogy, T. Anal. Sci. 2006, 22, 1351

20. Lemanska, K.; Szymusiak, H.; Tyrakowska, B.; Zielinski, R.; Soffers, A. E. M. F.; Rietjens, I. M. C. M. Free Radical Biol. Med. 2001, 31, 869.

21. Blasco, A. J.; Gonzalez, M. C.; Escarpa, A. Anal. Chim. Acta 2004, 511, 71.

22. Yang, B.; Kotani, A.; Arai, K.; Kusu, F. Anal. Sci. 2001, 17, 599.

23. Rice-Evans, C. A.; Miller, N. J.; Paganga, G. Free Radical Biol. Med. 1996, 20, 933.

24. Bors, W.; Heller, W.; Michel, C.; Saran, M. Methods Enzymol. 1990, 186, 343.

25. Brand-Williams, W.; Cuvelier, M. E.; Berset, C. Food Sci. Technol. 1995, 28, 25 (Lebensmittel Wissenschaft und Technologie).

26. Silva, A. M. S. Santos, C. M. M.; Cavaleiro, J. A. S. Tavares, H. R. Borges, F. Silva, F. A. M. In Magnetic Resonance in Food Science - A Science-A View to the Next Century; Webb, G. A., Belton, P. S., Gil, A. M., Delgadillo, I., Eds.; Royal Society Chemistry: Cambridge, 2001; pp 110-116.

27. Moridani, M. Y.; Galati, G.; O'Brien, P. J. Chem. Biol. Interact. 2002, 139, 251.

28. Santos, C. M. M.; Silva, A. M. S.; Cavaleiro, J. A. S. Eur. J. Org. Chem. 2003, 4575. 